\title{
APPLICATION OF SILICA AEROGEL IN COMPOSITES PROTECTING AGAINST THERMAL RADIATION
}

\author{
Sylwia Krzemińska ${ }^{1, *}, M$ Małgorzata Cieślak², Irena Kamińska ${ }^{2}$, Alicja Nejman $^{2}$ \\ 1 Central Institute for Labour Protection-National Research Institute (CIOP-PIB), Czerniakowska 16, 00-701 Warsaw, Poland \\ 2 Łukasiewicz Research Network - Textile Research Institute, Brzezińska 5/15, 92-103 Lodz, Poland \\ *Corresponding author. E-mail: sykrz@ciop.lodz.pl
}

\begin{abstract}
:
Aerogels are characterized by excellent insulation properties and a good resistance to high and low temperatures. The objective of this study was to investigate the effects of silica aerogel on thermal properties of textile-polymer composites. Aerogel was applied in protective clothing fabric to improve its heat resistance. The composites were produced by coating a fabric made of meta-aramid (polyamide-imide) yarns with a dispersion of polychloroprene latex and synthetic resins or an acrylic-styrene dispersion with aerogel (100-700 $\mu \mathrm{m}$ particle size). The composites were subjected to thermal radiation $\left(20 \mathrm{~kW} / \mathrm{m}^{2}\right)$ and their thermal properties were determined by thermogravimetry/ derivative thermogravimetry (TG/DTG). Scanning electron microscopy/X-ray energy dispersive spectroscopy (SEM/ EDS) was used to characterize the microstructure and study the elemental composition of materials. The thermal conductivity and resistance of composites were measured with an Alambeta apparatus. The tests indicated an increase in resistance to thermal radiation by approximately 15-25\%. In TG/DTG analysis, the initial temperature for an unmodified fabric was $423.3^{\circ} \mathrm{C}$. After modification, it decreased to $361.8^{\circ}$ and $365.3^{\circ} \mathrm{C}$ for composites with 7 and $14 \%$ of aerogel, respectively. SEM images revealed a reduction in aerogel particle size.
\end{abstract}

\section{Keywords:}

Resistance to radiation, exposure to radiant heat, silica aerogel, aerogel composites, thermal conductivity, SEM/ EDS, TG/DTG, protective clothing

\section{Introduction}

In many industries, workers are exposed to flames and other high-temperature factors, such as convective, radiant, and contact heat, which pose significant risks. Therefore, workers should be equipped with an appropriate protective clothing, gloves, and footwear [1]. The heat fluxes faced by workers range from several $\mathrm{kW} / \mathrm{m}^{2}$ for normal operations to $200 \mathrm{~kW} /$ $\mathrm{m}^{2}$ for firefighters exposed to flashover or backdraft [2]. Heat flux consists of convective and components. Importantly, radiant heat transfer depends on the radiation emitted by hightemperature sources and on properties of protective clothing materials $[2,3]$.

Given the serious potential consequences of heat-related hazards, researchers seek to modify materials used in the protective clothing to enhance their thermal resistance. Aerogel, a gel comprising a microporous solid in which the dispersed phase is the gas, is one of the materials which aroused the interest of researchers [4]. Due to their special structure, aerogels are characterized by very good insulation properties under conditions of both high and low temperatures. Silica aerogels are known to be unique porous materials with highly cross-linked network structures revealing a large specific surface area (500-1000 m²/g), high porosity, low density (0.02$0.2 \mathrm{~g} / \mathrm{cm}^{3}$ ), and very low thermal conductivity (approximately $0.013 \mathrm{~W} / \mathrm{mK})$ [5].
As a result, in recent years, silica aerogels have been used in a variety of advanced applications.-Aerogels are widely used: as fillers for the manufacture of paints and varnishes; as sensors and insulators in electronics; and as adsorbents and catalysts in chemical industries [6]. Due to excellent thermal insulation, which is approximately 100 times higher than that of glass, aerogels are used as insulators in refrigerators [7]. Aerogels made of organic polymers are important nanoporous materials, and their nanoporous structures can be modified by chemical reactions. These properties allow the use of aerogels for sensors, actuators, electrodes, and thermoelectric equipment. Porosity ensures both molecular accessibility and rapid transport by diffusion. For these reasons, aerogels are used in catalytic materials. However, the main application of aerogels is their use in thermally insulating materials [8]. Specifically, composites of lightweight materials and silica aerogels have been implemented in a high-speed aircraft for a thermal protection. The nonwoven materials produced with aerogel in the form of mats (blankets) are additionally characterized by good mechanical strength [7]. Therefore, they are applied, among others, in insulation of the walls, attics, or floors of buildings [9]. Aerogel blankets provide a higher level of insulation of the building than mineral wool or glass fiber. Nosrati and Berardi [9] have developed various aerogel-enhanced insulating materials and assessed their thermal properties under different operating temperatures and moisture content levels. They used commercial aerogel blankets and boards and prepared 
new aerogel-enhanced plasters using hydrophobized granular silica aerogel (with the concentration from 25 to 90 vol.\%). Nosrati and Berardi confirmed that the thermal conductivity of the materials was inversely proportional to the aerogel content. The thermal conductivity for high aerogel content samples (70, 80 , and 90 vol.\%) marginally changed with temperature. Contrary, in low aerogel content samples (0, 25, and 50 vol.\%) the temperature changes were more significant. Research has shown that the humidity and moisture content have a greater impact on the thermal conductivity than the temperature. The thermal conductivity of the aerogel-enhanced samples was significantly affected by relative humidity $(+46 \%$ under high relative humidity and $-4 \%$ under low relative humidity levels compared with the standard conditions). It should be noted that the changes in thermal properties of aerogel-enhanced insulations may affect the building energy.

Apart from the type of aerogel particles, the insulation material properties are influenced to a considerable extent by the type of the fibers used or fibrous matrix. In aerogel-enhanced materials, the fiber matrix supports the aerogel structure. Therefore, the type of matrix raw materials is very important. The issue of characterization of aerogel-enhanced blankets, produced with supercritical drying techniques taking into account the different variants of fiber composition, was investigated by Berardi and Zaidi [10]. They studied the structure of several aerogelenhanced blankets with different types of fibers: polyester and polyethylene terephthalate (PET), polyester/glass, glass, ceramic, and carbon. They noted that depending on the type of fibers, aerogel granules were dispersed and bound together in the materials in a different way. As it follows from the studies by Berardi and Zaidi, the significant variation in the average fiber diameter among the blankets can be the cause. The carbon fibers were characterized by a larger diameter than fiber glass. Dispersion and the type of fibers were reflected in the results of the study of thermal conductivity determining the insulation properties of the blankets. Berardi and Zaidi observed that thermal conductivity for the variants of aerogel-enhanced blankets with fiber glass was in most cases lower than for the variants of aerogel-enhanced blankets with carbon fiber. The thermal conductivity at $25^{\circ} \mathrm{C}$ was 0.016 and $0.024 \mathrm{~W} / \mathrm{mK}$, respectively.

The most desirable property of aerogels and materials with their content is the thermal conductivity, which is as low as possible. However, it should be emphasized that thermal conductivity is dependent on various factors, including temperature to a large extent. Fantucci et al. [11] evaluated the variation in the thermal conductivity of insulation panels considering aging at various times and temperatures. They observed a significant variation in the thermal conductivity with the increase in temperature. The difference in thermal conductivity between the samples tested at the temperature of $10^{\circ} \mathrm{C}$ and $40^{\circ} \mathrm{C}$ after 20 -month aging was $0.00098 \mathrm{~W} / \mathrm{mK}$ (approximately $20 \%$ ). The thermal conductivity was determined with the uncertainty at the level of approximately $2.5 \%$, thus the increase in thermal conductivity should be regarded as significant. The studies by Lorenzati et al. [12] confirmed the impact of experimental test conditions on the uncertainty of thermal conductivity measurements for insulation panels.
The thermal stability of aerogels and materials with their content remains a very important problem. It should be realized that the tested aerogel material contains not only silica, but also different organic groups as methyl, hydroxyl, and carbon. The heat treatments to aerogel materials could lead to structural changes and consequently to the loss of thermal stability and an increase in their thermal conductivity. The above was confirmed in the studies by Lakatos and Csarnovics [13]. During annealing of the samples up to $250^{\circ} \mathrm{C}$ they noted that the thermal conductivity changed up to $0.02 \mathrm{~W} / \mathrm{mK}$, but it was constant when they were annealed at $70^{\circ} \mathrm{C}$ for 6 weeks.

Aerogels have certain limitations associated with their brittleness and relatively high manufacturing costs (energyand time-intensive production process) [7, 14]. The insulation capacity of aerogel-containing materials is higher than that of traditional nonwoven insulation materials applied in the clothing. Aerogels can be used to obtain materials with a sub-nanoporous cage structure characterized by a very high surface area. As a result, the insulation capacity of aerogels is 2-6 times higher as compared with other widely used materials [7].

In clothing applications, aerogels were initially incorporated in materials designated for protection against negative temperatures, typically in the form of nonwoven textile composites consisting of silica aerogel matrix and reinforcing material [15]. A nonwoven containing aerogel, known under the brand name of Spaceloft, is used in the winter clothing, including the snowboard outerwear [7, 16]. Research on aerogel applications in materials protecting against heat factors has been conducted over the past several years. Shaid et al. [17] were the first authors to develop a wool-aramid fabric coated with a binder with aerogel particles for the firefighter protective clothing. Fabrics with aerogel coatings have been found to exhibit the increased thermal resistance.

In turn, Bhuiyan et al. [18] coated a cotton fabric with polyurethane and aerogel particles to protect against water and chemicals. Also Yan et al. [19] explored aerogel coatings to obtain fabrics with high thermal insulation performance. They impregnated commercially available cotton and PETknitted fabrics with silica aerogel via a straightforward dip-dry process. The fabrics were dipped in aqueous dispersions with varying aerogel content, dried at $60^{\circ} \mathrm{C}$ for $24 \mathrm{~h}$, and finally stacked in 1,3 , or 5 layers. The content of silica aerogel in the cotton-based hybrid fabrics was $21-56$ wt $\%$. Aerogel composites were also made using an aqueous acryl dispersion, a foaming agent, and ammonium polyphosphate as a flame retardant [20]. The mixture was stirred until a foamed binder was obtained. Subsequently, hydrophobic aerogel beads were added while stirring. The resulting aerogel paste was dried at $130^{\circ} \mathrm{C}$. Aerogel particles were treated as flame-retardant additives incorporated into a polymer matrix to improve the thermal stability, slow down the burning rate, and decrease the heat emission [21].

Chakraborty et al. [22] prepared aerogel-Nomex nonwoven composite felts as the middle layer in three-layered protective clothing for firefighters. He studied the effect of precursor 
concentration on the radiant heat protection and obtained good results. The use of aerogel-Nomex nonwoven fabric showed more than $100 \%$ increase in the heat protection time as compared with the conventional multilayered heat protective clothing assembly. According to Chakraborty et al., the higher thermal protection time, due to the heat transmission through the aerogel particles surrounding the fibrous network, is deferred by many mechanisms. The aerogel-Nomex nonwoven felt, which is a composite material of silica aerogel within the fibrous matrix, can be described as an optically thick layer of material. The heat transfer process through the aerogel nonwoven fabric can be considered as conduction dominated.

However, it is also necessary to take into account the physiological parameters that affect the user's comfort. According to Mandal et al. [23], one of such parameters is air permeability that was corroborated by Glombikova and Komarkova [24] who tested the thermal properties of knitted fabrics. Therefore, the application of coatings containing aerogels with different types of binders can be a promising approach to improving the resistance of protective materials against the heat exposure.

The aim of this study was to investigate the effects of silica aerogel application on thermal properties of textile-polymer composites. The novel aspect of this work was the use of silica aerogel to prepare pastes and coat the flame-retardant fabric to increase its heat resistance. This study focused on the thermal properties of composites with aerogel coatings as well as their structure and resistance to degradation on exposure to high temperatures. The composites were prepared by coating the fabric made of meta-aramid (polyamide-imide) yarns with a dispersion of polychloroprene latex and synthetic resins or an acrylic-styrene dispersion with aerogel (100-700 mm particle size). The obtained materials were subjected to thermal radiation $\left(20 \mathrm{~kW} / \mathrm{m}^{2}\right)$. The thermal properties of coatings and composites were determined by thermogravimetry/derivative thermogravimetry (TG/DTG). Scanning electron microscopy/Xray energy-dispersive spectroscopy (SEM/EDS) was used to characterize the microstructure of the obtained materials and study their elemental composition. An Alambeta apparatus was used to measure the thermal conductivity and thermal resistance of the composites. The presented interdisciplinary study explored the utility of composites with aerogel coatings for the protection of workers against thermal radiation.

\section{Materials and methods}

\subsection{Materials}

Textile-polymer composites with aerogel were made from the following materials:

- flame-retardant fabric S $(98 \%$ Kermel $®$ - meta-aramid fibers $/ 2 \%$ conductive fiber, mass per unit area $220 \pm 10 \mathrm{~g} /$ $\mathrm{m}^{2}$, twill weave $3 / 1 \mathrm{Z}$, with fluorocarbon finish, manufactured by Andropol S.A. Andrychów, Poland), designated as fabric $\mathrm{S}$,
- KCB acrylic-styrene dispersion with a dry weight of $60 \pm 3 \%$ (Bochemia, Radom, Poland) or a SAL dispersion of polychloroprene latex and synthetic resins with a dry weight of $53 \pm 2 \%$ (Bochemia, Radom, Poland), designated as KCB and SAL, respectively,

- flame retardant: either halogen-free reactive diethyl- $N, N$ bis(2-hydroxyethyl)-aminomethyl phosphonate, 85-95\%, density $1.15-1.16 \mathrm{~g} / \mathrm{cm}^{3}$ (PCC Group Brzeg Dolny, Poland), designated as FR 1 , or $45 \%$ aqueous solution of ammonium polyphosphate, concentration $100 \mathrm{~g} / \mathrm{dm}^{3}$, density 1.29 $1.31 \mathrm{~g} / \mathrm{cm}^{3}$ (Clariant Plastics \& Coatings $\mathrm{GmbH}$, Sulzbach am Taunus, Germany), designated as FR 2,

- wetting agent: aqueous solution of alkoxylated alcohols, concentration $>85 \%$, dry weight $>85 \%$, density $0.97 \mathrm{~g} / \mathrm{cm}^{3}$ (BYK-Chemie GmbH Wesel, Germany), designated as wa,

- aerogel granules of specifications given in Table 1 (Cabot Corporation Billerica, USA), designated as CG.

The tests also involved the uncoated fabric $S$ and fabric $S$ coated with an acrylic-styrene dispersion without aerogel for comparison purposes.

\subsection{Preparation of coating pastes}

A flame retardant and wetting agent were mixed for 2 min with aerogel in a glass vessel. Then, an appropriate amount of that mixture was added to a vessel containing the selected polymeric dispersion, gently stirring using a mechanical laboratory stirrer with a metal anchor impeller (Biomix, Poland) for $5 \mathrm{~min}$ at a minimum rotational speed of $30 \mathrm{rpm}$. The composition of coating pastes is given in Table 2 .

The pastes were applied onto 210 ' $297 \mathrm{~mm}$ fabric samples and spread using a metal roller weighing $0.25 \mathrm{~kg}$. The coated samples were dried for $30 \mathrm{~min}$ at $80^{\circ} \mathrm{C}$ in a Memmert laboratory drier (Germany). Ten sheets were prepared from each composite variants and each sheet was divided into samples for the tests. The samples for tests were collected on a random basis. The thickness and mass per unit area of textile composites were determined (Figure 1). Thickness was measured in 10 replicates in randomly selected locations of each tested material to ensure the uniformity. The tests were conducted according to EN ISO 5084:1996 using a disk micrometer with a diameter of $50.5 \mathrm{~mm}$ at a pressure of $1 \mathrm{kPa}$ (Modell Rainbow T, Schröder Prüftechnik, Germany) [26]. Mass per unit area was determined in triplicate for randomly selected samples according to EN 12127:1997 using $100 \times 100 \mathrm{~mm}$ samples [27]. These tests were carried out to assess the homogeneity of the prepared composites. It was noted that the values of standard deviation for thickness measurement were from 0.01 to $0.06 \mathrm{~mm}$, which was from 1.96 to $8.47 \%$ of the measured values. For the mass per unit area measurements, the values of standard deviation were from 0.78 to $38.61 \mathrm{~g} / \mathrm{m}^{2}$ $(0.34-8.58 \%$ of the measured values).

Figure 2 shows photographs of sample surface. 


\subsection{Methodology}

\subsubsection{Structural examination (SEM/EDS)}

SEM images were obtained using a Vega 3 unit (Tescan, Czech Republic) in a high vacuum mode and with an accelerating voltage of $20 \mathrm{kV}$, coupled to a $3 \mathrm{~nm}$ resolution detector of derivative electrons. The surface of samples was sputtered with gold in a vacuum sprayer (Quorum Technologies Ltd., UK). The measurements of particle aerogel size were conducted for 50 randomly selected samples. Elemental analysis was done using an INCA Energy EDS X-ray microanalyzer (Oxford Instruments Analytical, Great Britain) connected to a Vega 3 SEM, without sputtering. For each sample, five $\mathrm{X}$-ray spectra were recorded in five micro-areas (of $0.05 \mathrm{~mm}^{2}$ ) and the average value of elements content and standard deviation was calculated.

\subsubsection{Thermogravimetric analysis (TG/DTG)}

Samples of aerogel, coatings, and unmodified and coated fabrics were subjected to thermogravimetric (TG) analysis using a TG 209 F1 Libra apparatus (Netzsch, Germany) with $0.1 \mu \mathrm{g}$ resolution to determine their thermal stability. Samples were heated from $30^{\circ}$ to $850^{\circ} \mathrm{C}$ in a nitrogen atmosphere, at a heating rate of $10^{\circ} \mathrm{C} / \mathrm{min}$. Three samples taken from three randomly selected places of each tested material were studied. Samples were tested in a ceramic crucible with a volume of 85 $\mu \mathrm{L}$. Measurements were taken in the same position and under the same conditions.

\subsubsection{Resistance to thermal radiation}

The test involves the exposure of samples to thermal radiation for a certain period of time. The composites were exposed to thermal radiation with a heat flux density of $20 \pm 2 \mathrm{~kW} / \mathrm{m}^{2}$. During the tests, the time of calorimeter temperature increases when $12^{\circ}$ or $24^{\circ} \mathrm{C}$ was recorded. The main elements of the experimental stand were: a source of thermal radiation-a heater (Technical University of Lodz, Poland), a base for bringing the calorimeter closer to or further away from the radiation source, a sample holder, a calorimeter, and a computer with software recording temperature changes (ATT Tarnowski company, Poland) (Figure 3). The applied rectangular calorimeter $50.0 \times 50.3 \times 1.6 \mathrm{~mm}$ weighing $36.0 \mathrm{~g}$ was made of $99 \%$ pure copper. The calorimeter was curved along its longer side in an arc with a radius of $130 \mathrm{~mm}$. The tests were conducted according to the standard EN ISO 6942:2002 [28]. Samples $(240 \times 80 \mathrm{~mm})$ were mounted on the holder and placed on the front part of the calorimeter so that the surface with aerogel coating would face the calorimeter. A $200 \mathrm{~g}$ weight was attached to the bottom of samples to ensure that they remained in an appropriate position. The measurements were conducted for three randomly selected samples

The obtained data were used to calculate the radiant heat transfer index $\left(\mathrm{RHTI}_{24}\right)$ in accordance with EN ISO 11612:2015 [29]. $\mathrm{RHTI}_{24}$ is the shortest time of calorimeter temperature increase by $24.0 \pm 0.1^{\circ} \mathrm{C}$. The parameter was determined with $0.01 \mathrm{~s}$ resolution. $\mathrm{RHTI}_{24}$ was adopted as a measure
Table 1. Aerogel specifications $[15,25]$

\begin{tabular}{|c|c|}
\hline Parameter & Value \\
\hline Composition & $\begin{array}{c}\text { Silica [(trimethylsilyl)oxy]- } \\
\text { modified }\end{array}$ \\
\hline Particle size range & $100-700 \mathrm{~mm}$ \\
\hline Pore diameter & $\sim 20 \mathrm{~nm}$ \\
\hline Particle density & $120-150 \mathrm{~kg} / \mathrm{m}^{3}$ \\
\hline Surface chemistry & Hydrophobic \\
\hline Thermal conductivity & $12 \times 10^{-3} \mathrm{~W} / \mathrm{mK}$ \\
\hline BET surface area* & $740.7 \mathrm{~m}^{2} / \mathrm{g}$ \\
\hline Pore volume $^{*}$ & $5.04 \mathrm{~cm}^{3} / \mathrm{g}$ \\
\hline
\end{tabular}

* Previously described in Greszta et al. [15].

Table 2. Composition of coating pastes

\begin{tabular}{|c|c|c|c|c|}
\hline No. & Variant & \multicolumn{2}{|c|}{$\begin{array}{c}\text { Content of } \\
\text { components } \\
{[w t \%]}\end{array}$} & $\begin{array}{c}\text { Mass of } \\
\text { components } \\
\text { (dry matter) } \\
{[\mathrm{g}]}\end{array}$ \\
\hline \multirow{4}{*}{1} & \multirow{4}{*}{ KCB CG 0\% } & $A$ & 0.0 & 0.0 \\
\hline & & $\mathrm{D}$ & 100.0 & 45.0 \\
\hline & & FR & 0.0 & 0.0 \\
\hline & & wa & 0.0 & 0.0 \\
\hline \multirow{4}{*}{2} & \multirow{4}{*}{ SAL CG $17 \%$} & $A$ & 17.4 & 8.01 \\
\hline & & $\mathrm{D}$ & 82.6 & 37.9 \\
\hline & & FR & 0.0 & 0.00 \\
\hline & & wa & 0.0 & 0.00 \\
\hline \multirow{4}{*}{3} & \multirow{4}{*}{ KCB CG 6\% FR 1} & $A$ & 6.1 & 4.0 \\
\hline & & $\mathrm{D}$ & 69.6 & 45.6 \\
\hline & & $\mathrm{U}$ & 24.3 & 15.9 \\
\hline & & wa & 0.0 & 0.00 \\
\hline \multirow{4}{*}{4} & \multirow{4}{*}{$\begin{array}{c}\text { KCB CG } 7 \% \text { FR } \\
2 \text { wa }\end{array}$} & $A$ & 7.1 & 4.0 \\
\hline & & $\mathrm{D}$ & 80.6 & 45.6 \\
\hline & & FR & 11.1 & 6.3 \\
\hline & & wa & 1.2 & 0.7 \\
\hline \multirow{4}{*}{5} & \multirow{4}{*}{$\begin{array}{c}\text { KCB CG } 14 \% \text { FR } \\
2 \text { wa }\end{array}$} & $A$ & 14.4 & 8.0 \\
\hline & & $D$ & 77.9 & 43.2 \\
\hline & & FR & 6.5 & 3.6 \\
\hline & & wa & 1.2 & 0.7 \\
\hline
\end{tabular}

$\mathrm{A}$, aerogel; D, polymer dispersion (KCB or SAL); FR, flame retardant, wa, wetting agent.

for evaluating the performance of materials according to the classification shown in Table 3. According to EN ISO $11612: 2015$, the requirements of at least protection class 1 should be met. 


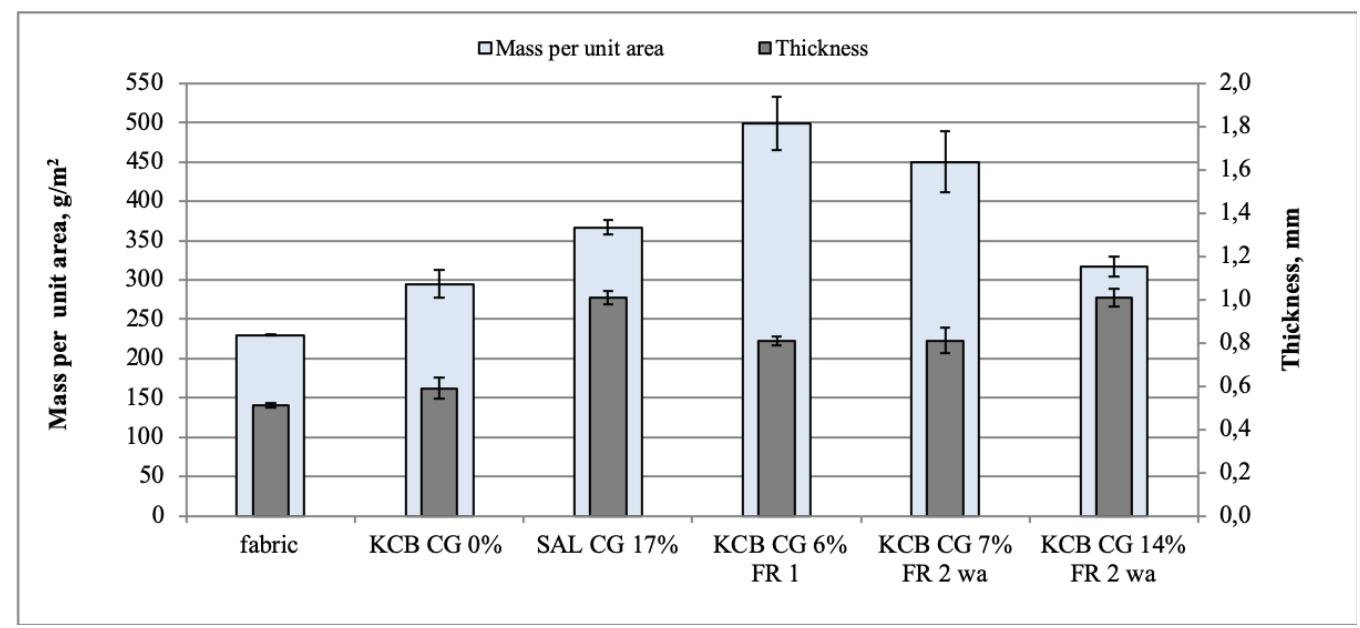

Figure 1. Thickness and mass per unit area of textile composites.

Table 3. Performance level classification according to the $\mathrm{RHTI}_{24}$

\begin{tabular}{|c|c|c|}
\hline \multirow{2}{*}{ Protection class } & \multicolumn{2}{|c|}{$\mathrm{RHTI}_{24}$ [s] } \\
\cline { 2 - 3 } & $\min$ & $\max$ \\
\hline C1 & 7.0 & $<20.0$ \\
\hline C2 & 20.0 & $<50.0$ \\
\hline C3 & 50.0 & $<95.0$ \\
\hline C4 & 95.0 & - \\
\hline
\end{tabular}
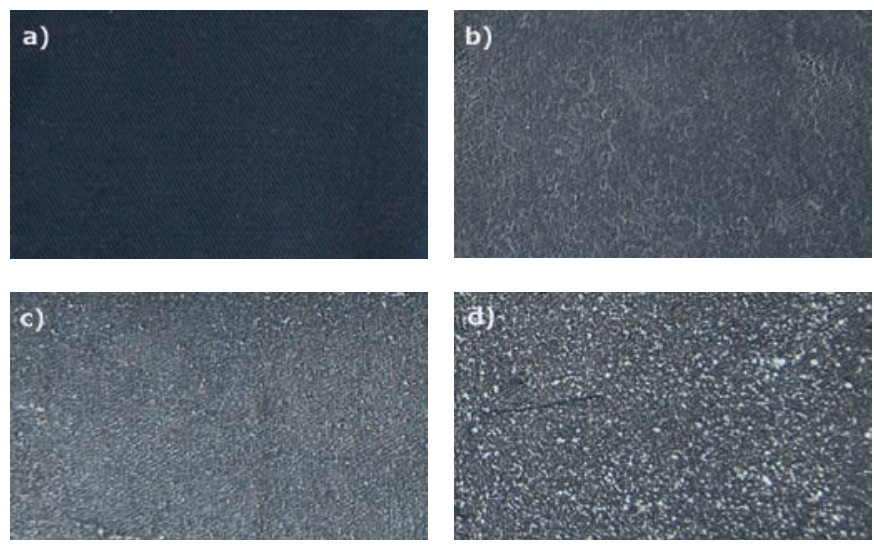

Figure 2. Photographs of the fabric surface $S$ : (a) unmodified, (b) coated without aerogel (KCB CG $0 \%$ ), (c) coated with $6 \%$ aerogel (KCB CG 6\% FR 1), and (d) coated with 14\% aerogel (KCB CG 14\% FR 2 wa).

\subsubsection{Thermal conductivity and resistance}

The thermal conductivity and thermal resistance of fabricpolymer composites containing aerogel were measured using an Alambeta apparatus (Sensora, Czech Republic). Samples $(170 \times 170 \mathrm{~mm})$ were $0.65-1.10 \mathrm{~mm}$ thick. The tests involved a measurement of the amount of heat transmitted through the composite sample placed between two plates (pressure $200 \pm 20 \mathrm{~Pa}$ ). The upper plate was heated to $32^{\circ} \mathrm{C}$ (human skin temperature), while the bottom plate had an ambient temperature of $22^{\circ} \mathrm{C}$ [30]. Five samples taken from three randomly selected places of each tested composite were
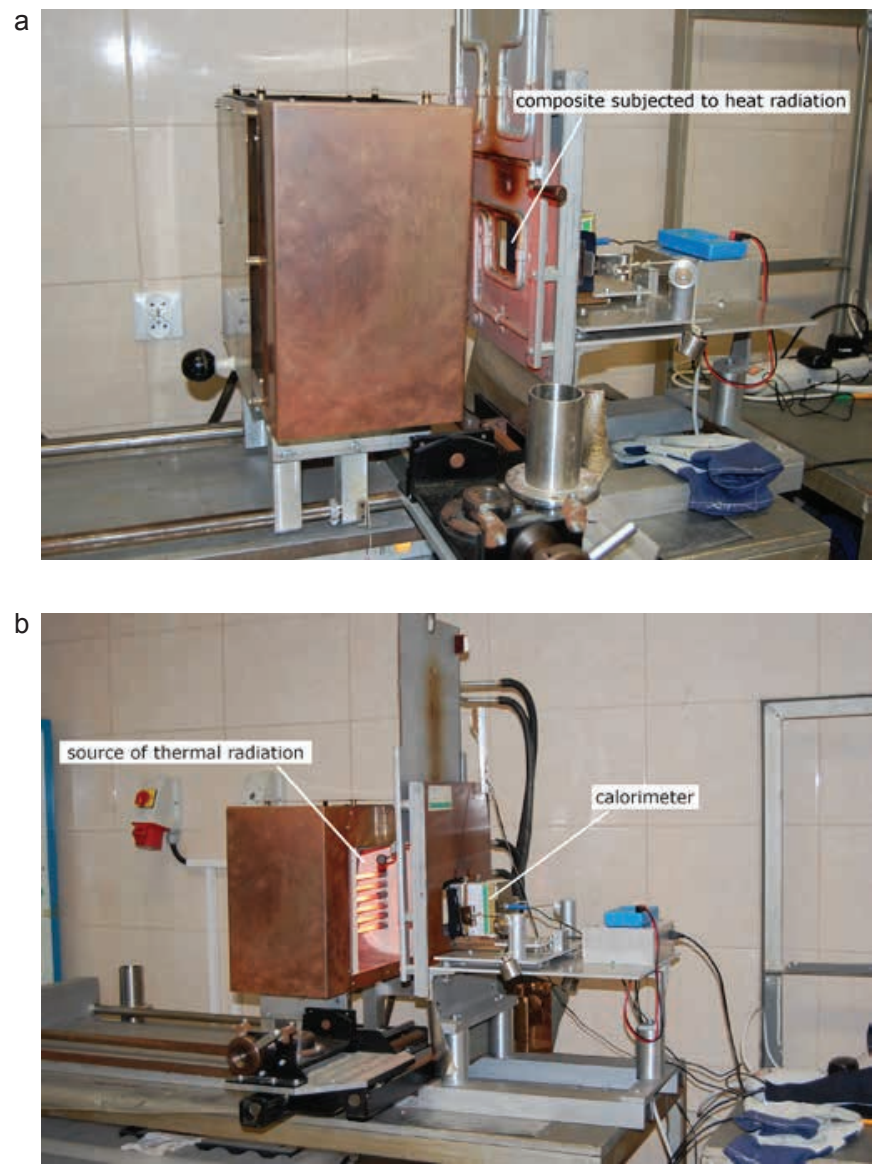

Figure 3. Experimental stand for measuring resistance to thermal radiation.

studied. The average value and standard deviation were calculated. The samples were tested on the side with aerogel coating. The thermal conductivity and thermal resistance of aerogel were determined as the difference between the results for two fabric layers separated by an aerogel layer $(1.1 \mathrm{~g})$ and those for two layers of fabric without aerogel. The parameters were determined with $10^{-5} \mathrm{~W} / \mathrm{mK}$ or $\mathrm{Km}^{2} / \mathrm{W}$ accuracy. 


\subsubsection{Statistical analysis}

Thermal conductivity and thermal resistance results were statistically analyzed using Statistica ver. 10.0 software from Statsoft Poland. Analysis of variance (ANOVA) was used, but if equality of variances was not confirmed by the Levene test, Welch's F-test was applied. Post-hoc multiple comparisons were performed by means of Tukey's RIR test.

Statistical analysis of thermal radiation data was conducted using the statistical package PQStat ver. 1.6.6.202 from PQStat Software, Poland. Depending on the group, the results were compared using the Kruskal-Wallis test (first, normality of distribution was examined using the Shapiro-Wilk test) or Dunn's post-hoc test with Bonferroni's correction. The significance level was adopted at $\alpha=0.05$.

The standard deviation was assumed as random uncertainty. Attempts were made to obtain the standard deviation constituting the lowest possible percentage of the measured value. In the case of the measurements of heat transfer index, the standard deviation, depending on the variant, was from 0.4 to $8.3 \%$ of the measured value. In turn, for the thermal conductivity measurements, depending on the variant, the standard deviation was from 2.6 to $9.7 \%$ of the measured value. In the case of thermal resistance, the obtained standard deviation was higher and for two composite variants (KCB CG 0\%, KCB CG 6\% FR 1) it was approximated 25\%. However, due to the limited number of sheets of composites prepared and the resulting limited number of samples for tests of the particular parameter, it was decided not to reject the results. We considered it important to compare two parameters for prepared composites: the thermal conductivity and the thermal resistance.

The standard errors of the average value of measured parameters were:

- from 0.03 to $0.70 \mathrm{~s}$ for heat transfer index,

- from $0.42 \times 10^{-3}$ to $1.79 \times 10^{-3} \mathrm{~W} / \mathrm{mK}$ for thermal conductivity, - from $1.16 \times 10^{-3}$ to $2.13 \times 10^{-3} \mathrm{Km}^{2} / \mathrm{W}$ for thermal resistance.

\section{Results and discussion}

\subsection{Aerogel effects on composite structure}

Figure 4 shows sample microscopic images of aerogel, the surface of uncoated fabric $S$, and the fabric $S$ with unmodified and modified coatings. Particle size measurements of $C G$ material and CG incorporated in coatings indicate that the size of aerogel particles was greatly reduced during the technological process, from $397.07 \pm 201.78 \mathrm{~mm}$ to $7.28 \pm 5.17 \mathrm{~mm}$ for KCB CG 6\% FR 1, which implies a 50-fold reduction in particle size. In the case of the composite KCB CG 6\% FR 1, small aerogel particles could be seen only at a magnification of 2,000 x (Figure $4 \mathrm{~h}$ ). Standard deviation values of aerogel size measurements were high and ranged from 50 to $90 \%$ of the measured values, despite a huge number of measurements (up to 50). As it was noted in the section Introduction, the aerogel fragmentation is one of the most serious problems associated with textile applications. Aerogel particle size reduction was somewhat less severe in the case of coatings consisting of wetting agent, flame retardant, and aerogel in a polymeric dispersion. In this case, the aerogel particle size was $13.10 \pm 9.04 \mathrm{~mm}$ for KCB CG 7\% FR 2 wa and $10.10 \pm 5.17 \mathrm{~mm}$ for KCB CG 14\% FR 2 wa (the difference is attributable to the greater friction forces during a paste preparation), which corresponds to a 30-40fold size reduction (Figure 5). The probable reason is that the aerogel was more resistant to crushing in coatings containing a wetting agent due to the fact that the latter decreased the surface tension of the aqueous phase of dispersion, while wetting the hydrophobic surface of aerogel particles and facilitating their adhesion to other components of the mixture. The resulting "shells" provided some protection to aerogel particles, lowering their susceptibility to crushing. It was found that both large agglomerates and small particles of aerogel were located side by side on the surface of the same sample. The authors hypothesized that the reason for this was the way the aerogel particles were attached to the surface of the composite samples, which was also observed in the study by Berardi and Zaidi [10].

Aerogel crushing during a test simulating the real use of footwear material was observed by Kraner et al. [31]. Those researchers studied silica aerogel composites made from a silica aerogel matrix embedded in a noncombustible reinforced fibrous matting material and laminated with a polyetherester block copolymer membrane. The flexing of the material revealed white areas indicating the presence of silica aerogel dust. Silica aerogel dust (>100 nm) arose from the broken particles of aerogel which migrated from the inner part of the composite to its surface. According to Kraner et al. [31], a lamination was an appropriate method for the preparation of aerogel composites for footwear applications.

In addition, Sarawade et al. [32] reported a reduction in the size of silica aerogel beads exposed to high temperature. SEM and transmission electron microscopic (TEM) images showed that the bead diameter dramatically decreased with increasing temperature. A temperature increase from 200 to $500^{\circ} \mathrm{C}$ resulted in a considerable rise of aerogel surface weight, with a concomitant reduction in a particle size from 524 to $776 \mathrm{~m}^{2} / \mathrm{g}$, while the pore volume and diameter increased only for samples exposed to temperatures of less than $500^{\circ} \mathrm{C}$.

Krzemińska et al. [33] reported that the exposure of aerogels to heat led to a reduction in their weight, but only at much higher temperatures. They observed a weight loss of approximately $2 \%$ at $180^{\circ} \mathrm{C}$ (irrespective of treatment time) as compared with approximately $7 \%$ at $350^{\circ} \mathrm{C}$ (a more than threefold increase). In turn, Williams et al. [34] studied polystyrene nanocomposites with different types of silica aerogels: $4 \mathrm{~mm}$ granules, ballmilled granules, and $80 \mu \mathrm{m}$ beads. In cone calorimetry tests with a heat flux of $35 \mathrm{~kW} / \mathrm{m}^{2}$, they observed disintegration of the mesoporous structure of aerogel, especially as a result of milling, which impaired the beneficial effects of aerogel. Williams et al. concluded that larger mesoporous aerogel particles absorbed the air and decreased heat transfer to the base polymer, delaying or reducing the heat release. Probably, due to the aerogel particle size reduction revealed by SEM, 

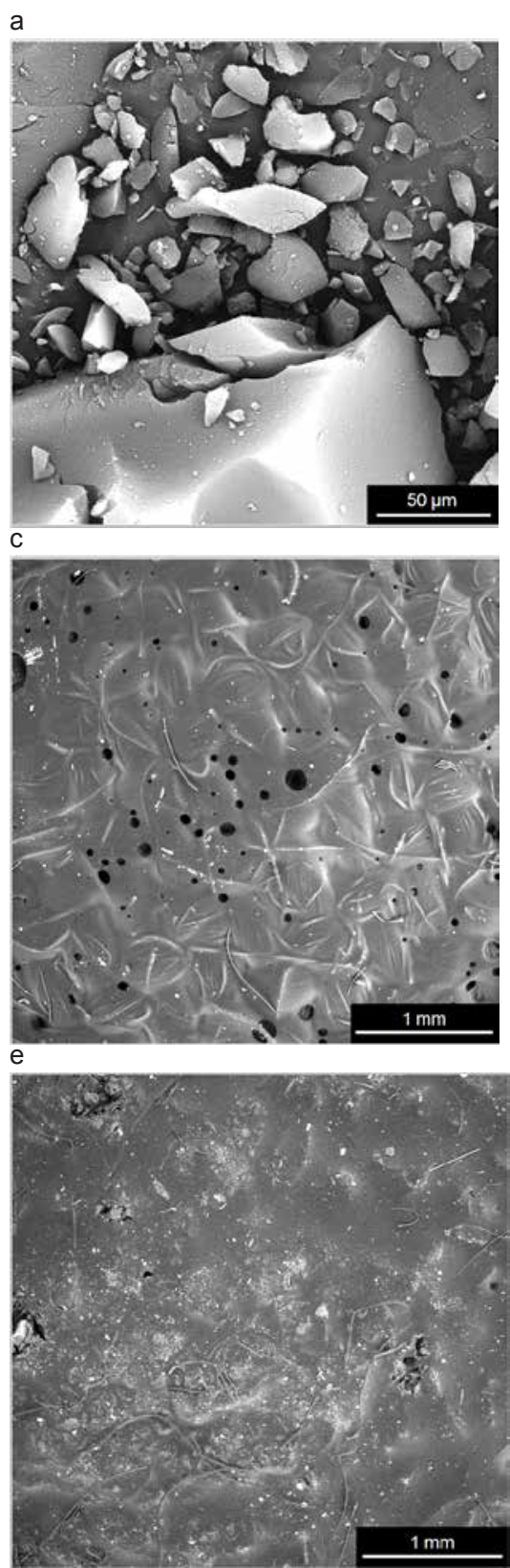

g

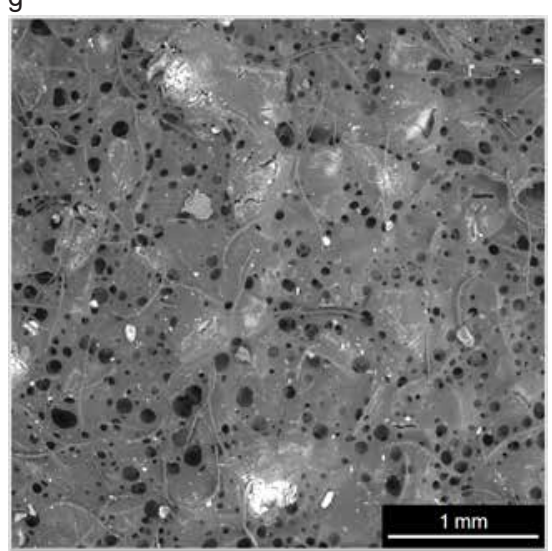

b
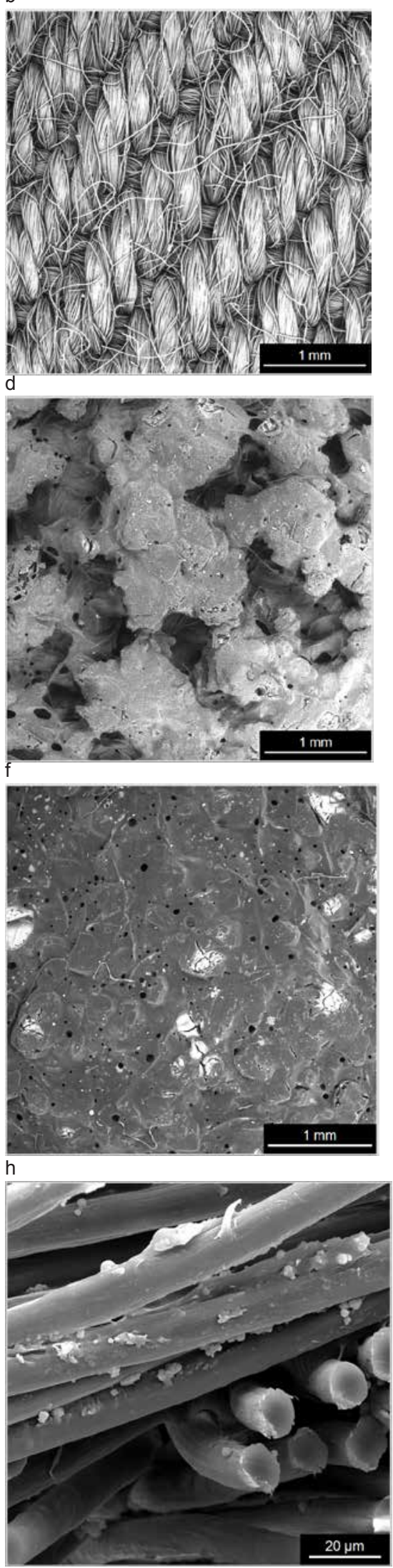

Figure 4. SEM images of (a) aerogel CG, (b) fabric S, (c) fabric S coated with KCB CG $0 \%$, (d) fabric S coated with SAL CG $17 \%$, (e) fabric $S$ coated with KCB CG 6\% FR 1, (f) fabric S coated with KCB CG 7\% FR 2 wa, (g) fabric S coated with KCB CG 14\% FR 2 wa, and (h) fabric S coated with KCB CG 6\% FR 1 (magnification 2,000x). 


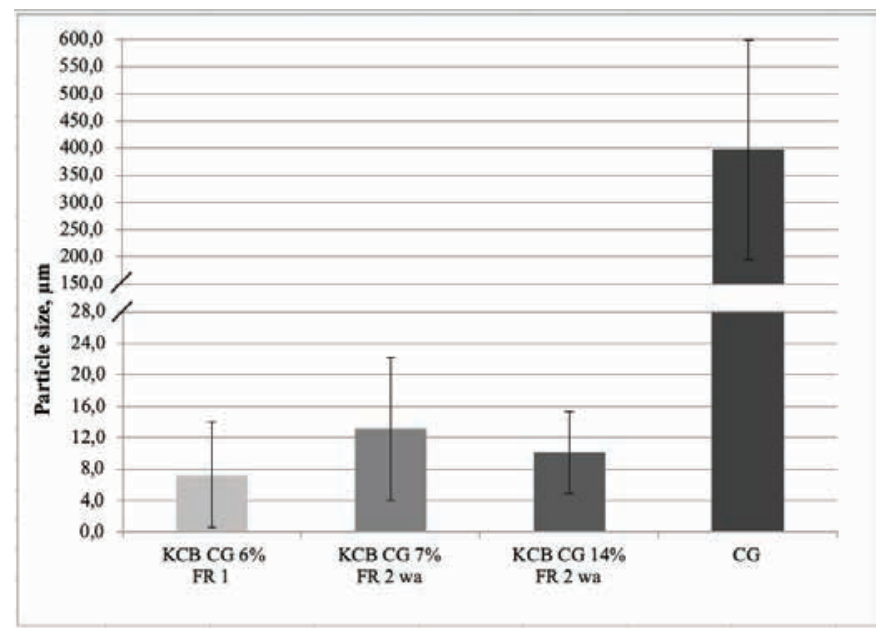

Figure 5. Aerogel particle sizes (CG) on composite surface as compared with new aerogel.

composites containing aerogel coatings exhibited only a slight increase in resistance to thermal radiation.

SEM/EDS analysis revealed variation in Si content depending on the paste composition and aerogel concentration in the KCB CG coating with a flame retardant (see Table 4). The values of standard deviation for average content of Si were $0.6-1.5$ $w t \%$ and for other elements they were $0.0-4.0$ wt $\%$, which corresponded to a maximum of $10 \%$ of the measured value.

\subsection{TG/DTG analysis}

TG/DTG data for the fabric, coatings, and the resulting composites are presented in Table 5. The values of standard deviation for average temperature values were $0.1-1.1^{\circ} \mathrm{C}$ and for average weight losses $0.14-1.34 \%$.

Figure 6 shows TG/DTG curves for different types of coatings and coated fabrics. The thermal degradation of aerogel CG started at $430.0^{\circ} \mathrm{C}$ with a maximum at $564.4^{\circ}$ and $710.2^{\circ} \mathrm{C}$. CG aerogel was thermally stable with a weight loss of $11.11 \%$ at $850^{\circ} \mathrm{C}$ (Figure $6 a$ and Table 5).
At the initial stage of heating, the TG curve for the coating KCB CG $0 \%$ revealed a slight weight loss in the range of $30-160^{\circ} \mathrm{C}$, which corresponded to the water desorption peak in the DTG curve in the same temperature range. The main thermal degradation occurred above $360^{\circ} \mathrm{C}$ with a maximum of $403.1^{\circ} \mathrm{C}$ in the DTG curve. The thermal degradation process of coating KCB CG 7\% FR2 wa started at the same temperature as for $\mathrm{KCB}$ CG $0 \%$. The weight loss at $850^{\circ} \mathrm{C}$ was comparable with $\mathrm{KCB}$ CG $0 \%$ and amounted to $90.45 \%$. The initial thermal degradation temperature obtained for the coating KCB CG 14\% FR2 wa was higher than for KCB CG 7\% FR2 wa by approximately $5^{\circ} \mathrm{C}$. The thermal degradation of coating $\mathrm{SAL}$ CG $17 \%$ started at $333.1^{\circ} \mathrm{C}$ and proceeded in three steps with maxima at $370.2^{\circ}, 440.7^{\circ}$, and $472.2^{\circ} \mathrm{C}$. In the temperature range of thermal degradation, the weight loss values were $52.12,15.61$, and $9.82 \%$, respectively.

In the initial stage of heating, the TG curve of reference fabric $S$ (Figure $6 \mathrm{~b}$ ) revealed a slight weight loss in the range of $30-120^{\circ} \mathrm{C}$, corresponding to the water desorption peak in the DTG curve in the same temperature range. The main thermal degradation occurred above $420^{\circ} \mathrm{C}$ with a maximum of $471.1^{\circ} \mathrm{C}$ in the DTG curve. The weight loss at about $850^{\circ} \mathrm{C}$ was $53.40 \%$.

Fabric S modified with KCB (acrylic-styrene) dispersion without CG aerogel (KCB CG 0\%) decomposed in two main steps in the temperature range of $360-613^{\circ} \mathrm{C}$. The TG curve showed a weight loss of about $27.57 \%$, corresponding to a peak in the DTG curve with a maximum at $391.3^{\circ} \mathrm{C}$, indicating thermal degradation of the KCB coating. The second weight loss of $26.00 \%$ corresponded to a peak in the DTG curve with a maximum at $460.4^{\circ} \mathrm{C}$, indicating the degradation of the fabric $\mathrm{S}$ itself. Interestingly, that peak shifted toward lower temperatures in comparison with the unmodified fabric S. Modification with a $\mathrm{KCB}$ coating without CG aerogel increased the weight loss to $65.74 \%$ at $850^{\circ} \mathrm{C}$.

The degradation of fabric KCB CG 6\% FR1 proceeded in three steps. In the first step, the initial thermal degradation temperature was above $150^{\circ} \mathrm{C}$ with a maximum of $222.3^{\circ} \mathrm{C}$, attributable to the decomposition of FR1 and resulting in a weight loss of $13.17 \%$. The second weight loss occurred above

Table 4. Elemental composition analysis

\begin{tabular}{|c|c|c|c|c|c|c|c|c|c|}
\hline \multirow{2}{*}{ Element } & \multicolumn{9}{|c|}{ Elemental composition [wt\%] } \\
\hline & C & $\mathbf{N}$ & 0 & $\mathbf{F}$ & $\mathrm{Na} / \mathrm{K}$ & Si & $\mathbf{P}$ & $\mathbf{S}$ & $\mathrm{Cl}$ \\
\hline Aerogel CG & $27.8 \pm 2.5$ & & $42.2 \pm 4.0$ & & & $29.7 \pm 1.5$ & $0.1 \pm 0.0$ & & $0.2 \pm 0.0$ \\
\hline Fabric S & $64.6 \pm 0.3$ & $10.3 \pm 0.3$ & $16.2 \pm 0.1$ & $8.8 \pm 0.1$ & & & & & $0.1 \pm 0.0$ \\
\hline KCB CG 0\% & $71.7 \pm 0.1$ & & $28.0 \pm 0.1$ & & & & & $0.2 \pm 0.00$ & $0.1 \pm 0.0$ \\
\hline SAL CG $17 \%$ & $63.0 \pm 3.9$ & & $12.4 \pm 3.1$ & & $\begin{array}{l}0.3 \pm 0.0 \\
0.3 \pm 0.0\end{array}$ & $2.8 \pm 0.9$ & & $0.2 \pm 0.0$ & $21.0 \pm 0.1$ \\
\hline $\begin{array}{c}\text { KCB CG 6\% } \\
\text { FR } 1\end{array}$ & $66.6 \pm 1.1$ & & $27.9 \pm 0.5$ & & & $1.3 \pm 0.6$ & $1.0 \pm 0.0$ & $0.2 \pm 0.0$ & $3.0 \pm 0.1$ \\
\hline $\begin{array}{c}\text { KCB CG } 7 \% \text { FR } \\
2 \text { wa }\end{array}$ & $64.5 \pm 1.4$ & & $31.0 \pm 0.6$ & & & $2.3 \pm 1.2$ & $1.6 \pm 0.1$ & $0.1 \pm 0.0$ & $0.5 \pm 0.1$ \\
\hline $\begin{array}{l}\text { KCB CG 14\% } \\
\text { FR } 2 \text { wa }\end{array}$ & $63.0 \pm 1.4$ & & $31.8 \pm 0.3$ & & & $3.2 \pm 1.4$ & $1.7 \pm 0.1$ & $0.1 \pm 0.0$ & $0.2 \pm 0.0$ \\
\hline
\end{tabular}




\begin{tabular}{|c|c|c|c|c|c|c|c|c|c|c|c|c|c|}
\hline 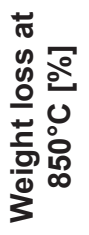 & & 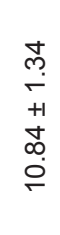 & $\begin{array}{l}\hat{\infty} \\
0 \\
+1 \\
+1 \\
0 \\
\infty \\
\infty \\
\infty\end{array}$ & 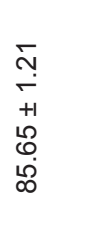 & 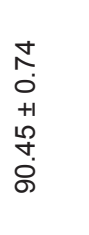 & $\begin{array}{l}8 \\
\stackrel{8}{ } \\
+1 \\
\stackrel{1}{0} \\
\stackrel{8}{8} \\
8\end{array}$ & & 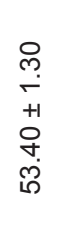 & 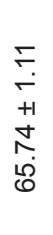 & $\begin{array}{l}\infty \\
o \\
0 \\
+1 \\
+1 \\
0 \\
\dot{8}\end{array}$ & 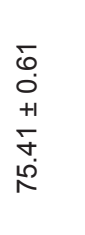 & $\begin{array}{l}\qquad 0 \\
0 \\
0 \\
+1 \\
0 \\
0 \\
0 \\
0 \\
0\end{array}$ & $\begin{array}{l}\hat{N} \\
\stackrel{1}{+} \\
+1 \\
\stackrel{\rho}{\rho} \\
\stackrel{1}{0}\end{array}$ \\
\hline 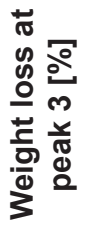 & & & & $\begin{array}{l}8 \\
0 \\
0 \\
+1 \\
\infty \\
\infty \\
\infty\end{array}$ & & & & & $\begin{array}{l}0 \\
0 \\
0 \\
+1 \\
8 \\
0 \\
0 \\
0\end{array}$ & \begin{tabular}{l}
$\infty$ \\
\multirow{0}{*}{} \\
+1 \\
$\stackrel{+}{0}$ \\
$\stackrel{m}{m}$ \\
$\dot{m}$
\end{tabular} & 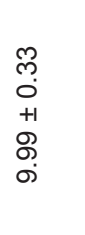 & \begin{tabular}{l}
0 \\
$\stackrel{0}{*}$ \\
$\circ$ \\
+1 \\
\multirow{+}{*}{} \\
$\infty$
\end{tabular} & $\begin{array}{l}m \\
m \\
0 \\
+1 \\
\stackrel{+}{0} \\
\stackrel{0}{\circ}\end{array}$ \\
\hline 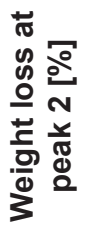 & & & & 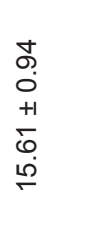 & & & & $\begin{array}{l}\tilde{\sigma} \\
0 \\
+1 \\
\bar{N} \\
\ddot{g}\end{array}$ & 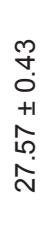 & $\begin{array}{l}\stackrel{m}{0} \\
0 \\
+1 \\
\stackrel{D}{0} \\
\stackrel{\sim}{D}\end{array}$ & 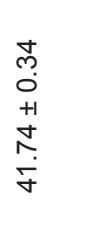 & 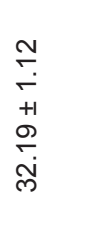 & $\begin{array}{l}8 \\
\infty \\
0 \\
+1 \\
\text { ' } \\
8 \\
0 \\
0\end{array}$ \\
\hline 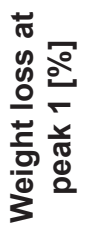 & & & \begin{tabular}{l}
\multirow{N}{N}{} \\
0 \\
+1 \\
0 \\
0 \\
$\infty$ \\
$\infty$
\end{tabular} & 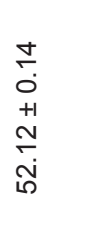 & 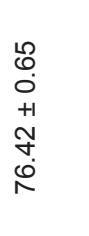 & 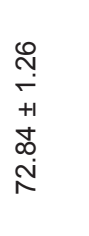 & & & & & 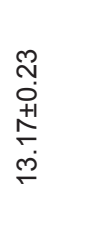 & & \\
\hline 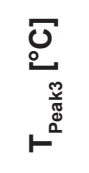 & & & & 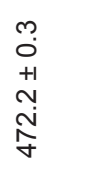 & & & $\stackrel{\mathscr{n}}{\mathscr{U}}$ & $\begin{array}{l}r \\
\dot{r} \\
+1 \\
\dot{r} \\
\dot{r}\end{array}$ & $\begin{array}{l}\hat{0} \\
0 \\
+1 \\
+ \\
0 \\
0 \\
0\end{array}$ & $\begin{array}{l}0 \\
0 \\
+1 \\
+1 \\
\dot{0} \\
\dot{0}\end{array}$ & $\begin{array}{l}0 \\
0 \\
+1 \\
0 \\
00 \\
0 \\
\dot{\sigma}\end{array}$ & $\begin{array}{l}0 \\
0 \\
+1 \\
0 \\
0 \\
0 \\
i\end{array}$ & $\begin{array}{l}\check{+} \\
+1 \\
+ \\
0 \\
0 \\
i\end{array}$ \\
\hline 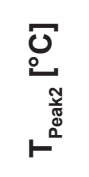 & & & & $\begin{array}{l}n \\
0 \\
+1 \\
\stackrel{1}{0} \\
\dot{g} \\
\dot{y}\end{array}$ & & & ठ̊ & & $\begin{array}{l}m \\
0 \\
+1 \\
m \\
\dot{m} \\
\dot{m}\end{array}$ & $\begin{array}{l}\hat{0} \\
+1 \\
+1 \\
0 \\
0 \\
m\end{array}$ & 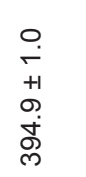 & $\begin{array}{l}0 \\
0 \\
+1 \\
o \\
\infty \\
\infty \\
\infty\end{array}$ & $\begin{array}{l}0 \\
0 \\
+1 \\
0 \\
\infty \\
0 \\
m\end{array}$ \\
\hline 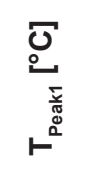 & & & $\begin{array}{l}0 \\
0 \\
+1 \\
+ \\
\ddot{m} \\
\dot{q}\end{array}$ & $\begin{array}{l}\hat{0} \\
0 \\
+1 \\
N \\
0 \\
0 \\
0\end{array}$ & 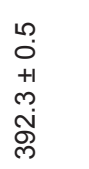 & $\begin{array}{l}0 \\
0 \\
+1 \\
0 \\
\dot{0} \\
\dot{m}\end{array}$ & & & & & $\begin{array}{l}\hat{0} \\
+1 \\
+ \\
\stackrel{N}{N} \\
\text { Na }\end{array}$ & & \\
\hline 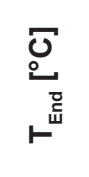 & & & $\begin{array}{l}m \\
0 \\
++ \\
o \\
\stackrel{+}{0} \\
\stackrel{y}{y}\end{array}$ & $\begin{array}{l}N \\
o \\
+1 \\
+ \\
\dot{+} \\
\dot{\sigma}\end{array}$ & $\begin{array}{l}\check{+} \\
+1 \\
0 \\
\dot{\sim} \\
\dot{y}\end{array}$ & $\begin{array}{l}\infty \\
0 \\
+1 \\
+1 \\
\dot{0} \\
\stackrel{0}{\sigma} \\
\dot{\sigma}\end{array}$ & & 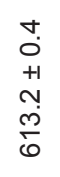 & $\begin{array}{l}\infty \\
0 \\
+1 \\
+ \\
0 \\
\dot{m} \\
\dot{0}\end{array}$ & $\begin{array}{l}\check{+} \\
+1 \\
0 \\
\stackrel{0}{0} \\
0\end{array}$ & $\begin{array}{l}\infty \\
0 \\
++1 \\
+\infty \\
\stackrel{0}{+} \\
\dot{0}\end{array}$ & $\begin{array}{l}0 \\
0 \\
+1 \\
\infty \\
0 \\
\stackrel{0}{0}\end{array}$ & 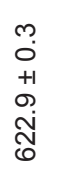 \\
\hline 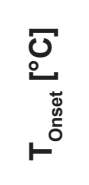 & & & $\begin{array}{l}0 \\
0 \\
+1 \\
+1 \\
\dot{+} \\
\dot{0}\end{array}$ & $\begin{array}{c}N \\
o \\
+1 \\
\stackrel{\infty}{\infty} \\
\ddot{m}\end{array}$ & $\begin{array}{l}\check{0} \\
+1 \\
0 \\
\ddot{\tilde{O}} \\
0 \\
\tilde{0}\end{array}$ & $\begin{array}{l}\forall \\
0 \\
+1 \\
+1 \\
0 \\
00 \\
0 \\
0\end{array}$ & & 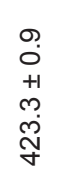 & 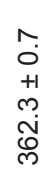 & \begin{tabular}{l}
\multirow{0}{0}{} \\
+1 \\
+ \\
0 \\
$\dot{d}$ \\
$\dot{m}$
\end{tabular} & $\begin{array}{l}6 \\
0 \\
++1 \\
0 \\
0 \\
0 \\
0 \\
0\end{array}$ & $\begin{array}{l}\check{r} \\
+1 \\
\infty \\
\dot{0} \\
\dot{\infty}\end{array}$ & $\begin{array}{l}0 \\
0 \\
+1 \\
0 \\
0 \\
0 \\
0\end{array}$ \\
\hline$\frac{\vec{\pi}}{\frac{\vec{\sigma}}{\pi}}$ & & $\begin{array}{l}\text { U } \\
\text { ब } \\
\mathbb{O} \\
\frac{0}{\mathbb{Q}}\end{array}$ & 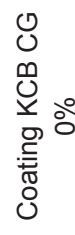 & 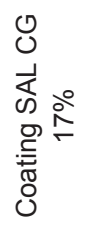 & 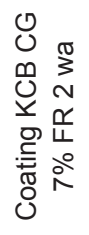 & 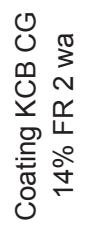 & & $\begin{array}{l}\infty \\
0 \\
\frac{0}{0} \\
\widetilde{0} \\
\leftarrow\end{array}$ & $\begin{array}{l}\stackrel{0}{0} \\
0 \\
0 \\
0 \\
0 \\
y\end{array}$ & 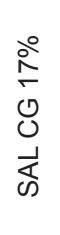 & 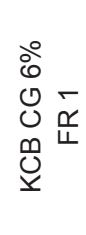 & 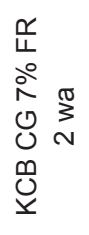 & 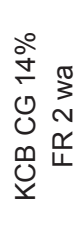 \\
\hline
\end{tabular}

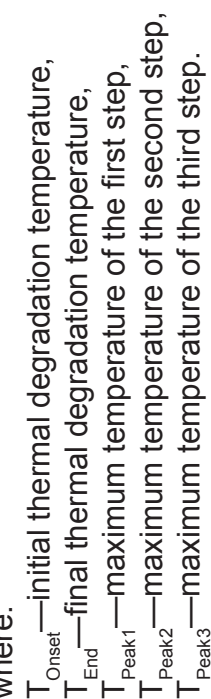


a)

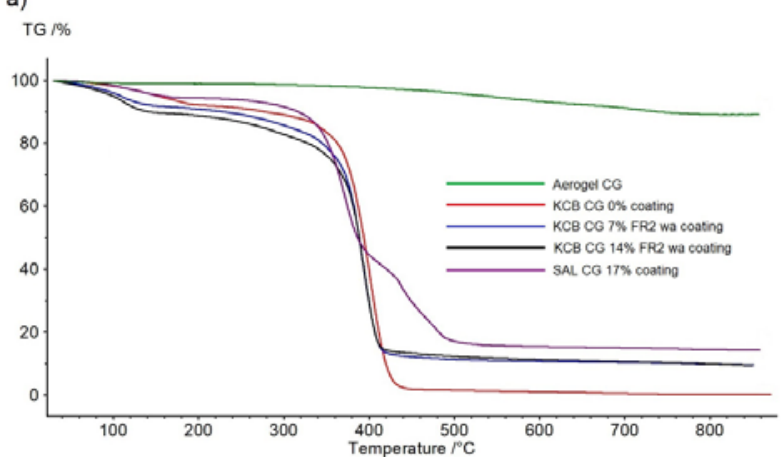

DTG /(\%/min)

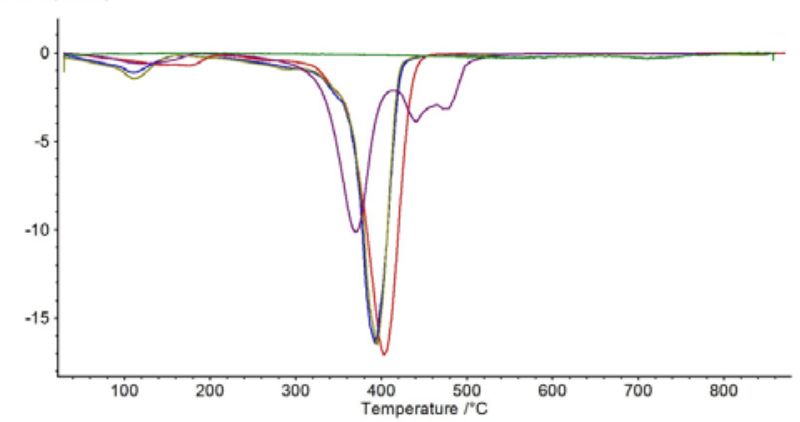

Figure 6. TG/DTG curves for (a) coatings and (b) coated fabric.

$300^{\circ} \mathrm{C}$, which corresponded to the KCB CG 6\% FR1 coating with the peak temperature shifted toward higher values by about $4^{\circ} \mathrm{C}$ in comparison with KCB CG $0 \%$. In the third step, the addition of FR1 and $6 \%$ of $\mathrm{CG}$ did not cause significant changes in the temperature of fabric $S$ in comparison with $\mathrm{KCB}$ CG $0 \%$. The weight loss at $850^{\circ} \mathrm{C}$ increased by about $10 \%$ in comparison with $\mathrm{KCB}$ CG $0 \%$ fabric.

The thermal degradation of fabric KCB CG 7\% FR2 wa started at the similar temperature to that for KCB CG $0 \%$ and proceeded in two steps. In step 1, the maximum temperature of KCB CG 7\% FR2 wa coating decomposition was higher by $7.6^{\circ} \mathrm{C}$. In step 2 (fabric decomposition), the maximum peak temperature shifted upward by about $50^{\circ} \mathrm{C}$ in comparison with KCB CG 0\%. The weight losses recorded during the first and second degradation steps were higher by about $5 \%$ and lower by about $18 \%$, respectively, as compared with the fabric KCB CG $0 \%$. The weight loss at $850^{\circ} \mathrm{C}$ was $56.03 \%$. The addition of $7 \%$ of aerogel, a flame retardant, and a wetting agent improved the thermal stability of KCB CG 7\% FR2 wa in comparison with KCB CG $0 \%$. The replacement of FR1 with FR2 decreased the weight loss and increased the degradation temperature of fabric S.

The thermal degradation temperatures obtained for KCB CG $14 \%$ FR2 wa (Figure 4f) were the same as those for KCB CG $7 \%$ FR2 wa. The degradation of the SAL CG $17 \%$ composite started at $341.6^{\circ} \mathrm{C}$ and proceeded in two steps with maxima at $376.0^{\circ}$ and $464.1^{\circ} \mathrm{C}$, corresponding to the degradation of the coating and fabric, respectively. Within the thermal degradation temperature range of two steps, the weight loss values amounted to 23.35 and $31.62 \%$, respectively.

The amount of aerogel added to fabric coatings was too low to show in TG/DTG curves (Figure 6).
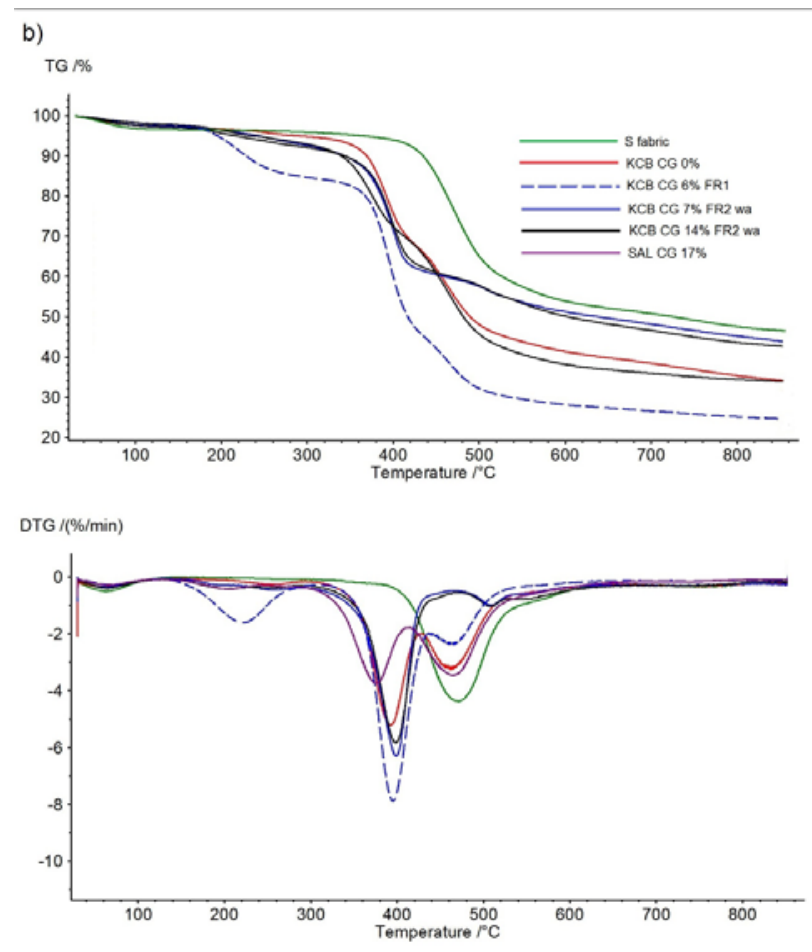

\subsection{Effects of aerogel on thermal radiation}

Measurements of the obtained composites revealed that aerogel application in the fabric coatings slightly improved their resistance to radiation. The $\mathrm{RHTI}_{24}$ of composites with lower aerogel content ( 6 or $7 \%$ ) was similar to that of the uncoated fabric (Figure 7). In turn, composites with the higher aerogel content in the coatings (KCB CG 14\% FR 2 wa and SAL CG $17 \%$ ) exhibited an improvement in $\mathrm{RHTI}_{24}$ by approximately $15-25 \%$. The significance of those differences was confirmed by a statistical analysis $(p=0.017)$. The heat transfer index $\mathrm{RHTI}_{24}$ measurements can be considered as repetitive. The values of standard deviation were $0.20-1.21 \mathrm{~s}$ (Figure 7 ). This represents from 0.36 to $8.34 \%$ of the measured index $\mathrm{RHTI}_{24}$.

Dispersions of polychloroprene latex and synthetic resin (SAL CG $17 \%$ ) led to the better resistance to thermal radiation as compared with acrylic-styrene dispersions (KCB CG 14\% FR 2 wa) (Figure 7). The difference amounted to $1.5 \mathrm{~s}$ and was statistically significant $(p=0.017)$. A similar effect was exerted on $\mathrm{RHTI}_{24}$ by both flame retardants. The difference between composites containing coatings with 6 or $7 \%$ of aerogel and those containing flame retardants was $1.6 \mathrm{~s}$ (Figure 8). Thus, the aqueous solution of ammonium polyphosphate was more useful as it led to higher $\mathrm{RHTI}_{24}$ both at 7 and $14 \%$ of aerogel content (approximately $2 \mathrm{~s}$ ).

It should be noted that the obtained composites were characterized by the resistance to thermal radiation ranging from 13 to $17 \mathrm{~s}$, means that all variants were assigned to the first protection class (7-20 s) according to EN 11612:2015 (see Table 3) [29]. The heat flux of $20 \mathrm{~kW} / \mathrm{m}^{2}$ used in the present study did not burn or melt the composites with aerogel coatings and the sample surface did not reveal any differences. In turn, $\mathrm{Li}$ et al. [35], who exposed glass fiber films with aerogel wrapped 
in an aluminum foil to heat fluxes of 35 and $60 \mathrm{~kW} / \mathrm{m}^{2}$, observed that composites became slightly yellowish. The higher heat flux of $60 \mathrm{~kW} / \mathrm{m}^{2}$ resulted in a partial combustion of composites, leaving behind black charred remains and white silica residues. Song et al. [36] reported a visible flame in their studies of silica aerogels using a cone calorimeter at a heat flux of $50 \mathrm{~kW} / \mathrm{m}^{2}$. The flame emergence time was $6 \mathrm{~s}$. They observed no flame at or below $40 \mathrm{~kW} / \mathrm{m}^{2}$. The time, after which large amounts of heat were released, was approximately $80-100 \mathrm{~s}$. Under the present testing conditions, the composites were exposed to a heat flux of $20 \mathrm{~kW} / \mathrm{m}^{2}$ for $10 \mathrm{~s}$ and no flames were observed. As can be seen, the radiant flux intensity is essential.

Chakraborty et al. [22] also obtained a significant improvement of the resistance to radiant heat after the application of silica aerogel to produce aerogel-Nomex nonwoven composite which was used by him as the middle layer in three-layered firefighters clothing.

The protection time of the fabric assembly in protective clothing, outer fabric-Nomex woven, middle layer-aerogel + Nomex nonwoven, inner layer-modacrylic/cotton woven after the exposure to heat flux of $\sim 35.0 \mathrm{~kW} / \mathrm{m}^{2}$, increased from $40 \mathrm{~s}$ for the lowest concentration of the precursor to over $80 \mathrm{~s}$ for the highest concentration (15.4 and 46.2 molar ratio, respectively). Thus, there was a twofold increase in the protection time. Chakraborty et al. pointed to the problem of dust shedding during the preparation of the Nomex-aerogel-based fabric assemblies, which was also observed by the authors of this paper.

\subsection{Effects of aerogel on thermal conductivity and resistance}

The produced thermal insulating composites with aerogel coatings were characterized by the slightly higher thermal conductivity than the uncoated meta-aramid fiber fabric (Figure 8). The coating of fabric with a polymeric dispersion increased its thermal conductivity from $35.70 \pm 0.95 \times 10^{-3} \mathrm{~W} /$ $\mathrm{mK}$ to $42.00 \pm 3.29 \times 10^{-3} \mathrm{~W} / \mathrm{mK}$. Statistical analysis showed significant differences between the unmodified fabric sample, the sample coated with the acrylic-styrene dispersion alone, and composites with aerogel coatings $(p=0.0002$ and $=0.0003)$. The highest thermal conductivity (47.94 $\pm 4.00 \times 10^{-3} \mathrm{~W} /$ $\mathrm{mK}$ ) was found for the composite with a coating containing $6 \%$ of aerogel and FR 1 . The other composites coated with mixtures containing FR 2 exhibited the thermal conductivity of $39 \times 10^{-3} \mathrm{~W} / \mathrm{mK}$, irrespective of aerogel concentration (Figure 8 ). The values of standard deviation ranged from $0.95 \times 10^{-3} \mathrm{~K}$ to $4.00 \times 10^{-3} \mathrm{~W} / \mathrm{mK}$. This represents an average of about $4 \%$ of the measured thermal conductivity.

In the study conducted by Collin et al. [2], a thermal conductivity of $81 \times 10^{-3} \mathrm{~W} / \mathrm{mK}$ was obtained for the outermost layer of firefighter protective clothing made of $0.7 \mathrm{~mm}$ thick synthetic fibers. The conductivity of synthetic fibers themselves was typically in the range of $40-80 \times 10^{-3} \mathrm{~W} / \mathrm{mK}$. As can be seen, there is a substantial difference in the thermal conductivity between the fabric used by Collin et al. and the fabric $S$ coated with polymeric mixtures containing aerogel, even though the fabric S was made of synthetic fibers (meta-aramid polyamideimide yarns). The overall thermal conductivity of composites may be modified by aerogel, which is characterized by the lowest thermal conductivity found for solids (in this case, only $12 \times 10^{-3} \mathrm{~W} / \mathrm{mK}$ according to the data sheet) [23]. Similar results were obtained in the present study-9.8 $\times 10^{-3} \mathrm{~W} / \mathrm{mK}$ (Figure 8). Furthermore, the thermal conductivity in the range of $19-23 \times 10^{-3} \mathrm{~W} / \mathrm{mK}$ was reported by the authors of a patent on an aerogel blanket made by impregnating the surface-treated glass felt with silica sol [37]. In the present work, aerogel application in a textile-polymeric composite led to a 4-5-fold increase in the thermal conductivity, reducing its resistance to heat transfer. This may be explained by the compromised structure of aerogel, which affected its properties. It should be noted that Shang et al. [38] observed changes in the thermal conductivity of silica aerogel composites under the influence

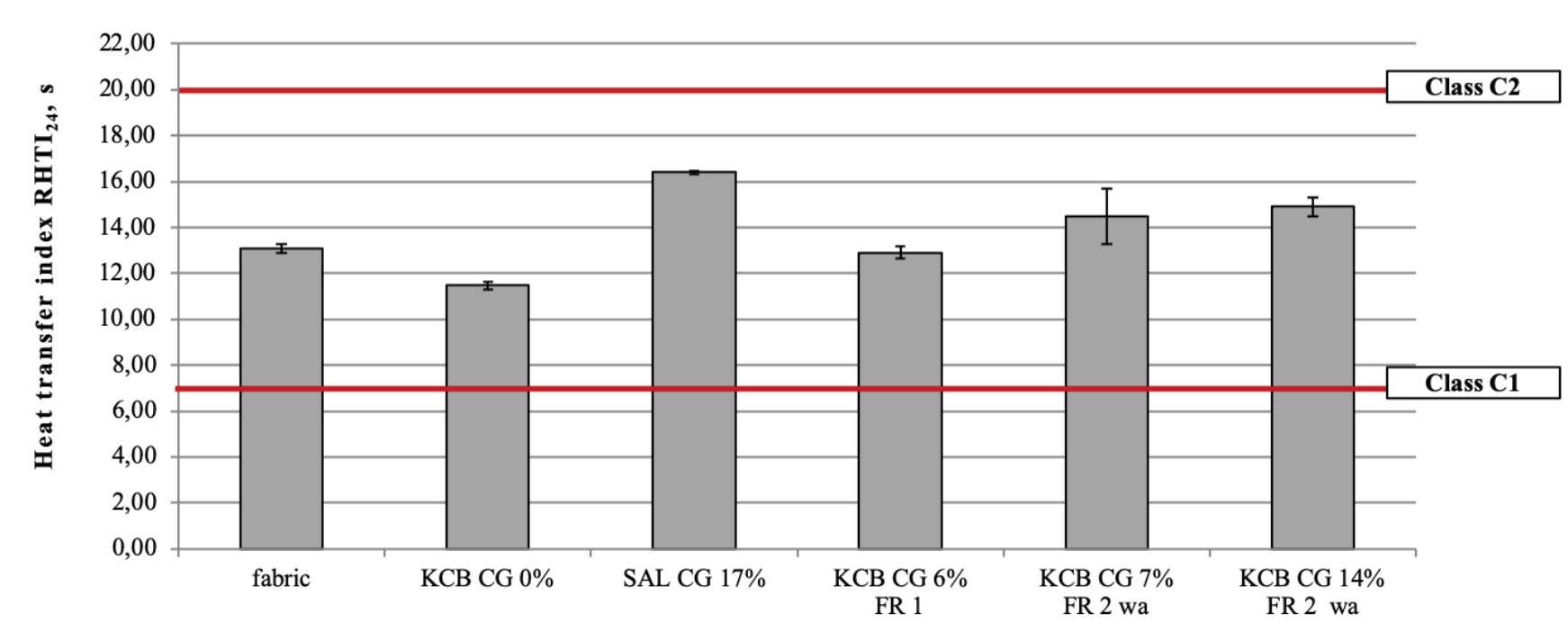

Figure 7. $\mathrm{RHTI}_{24}$ for composites containing coatings with and without aerogel. 
of high temperature. In that case, the thermal conductivity was $19.1 \times 10^{-3} \mathrm{~W} / \mathrm{mK}$ at the room temperature and $48.9 \times 10^{-3} \mathrm{~W} /$ $\mathrm{mK}$ at $500^{\circ} \mathrm{C}$.

It was observed that the thermal resistance of composites with the aerogel coating was similar to that of the uncoated metaaramid fabric and much lower (by approximately $40 \%$ ) than that of the fabric coated with polymeric dispersion without aerogel. The thermal resistance of composites with aerogel coatings was approximately $25-29 \times 10^{-3} \mathrm{~K} \cdot \mathrm{m}^{2} / \mathrm{W}$ (Figure 8). The exception was the composite coated with a mixture containing the flame retardant FR 1, the thermal resistance of which was significantly lower at $18.6 \pm 4.5 \times 10^{-3} \mathrm{Km}^{2} / \mathrm{W}(p=0.0117)$. The thermal resistance measurements have been characterized by the values of standard deviation from $2.60 \times 10^{-3} \mathrm{~K}$ to $4.77 \times 10^{-3} \mathrm{~K} \cdot \mathrm{m}^{2} / \mathrm{W}$, which corresponded to $3.34-26.27 \%$ of the measured value.

Xiong et al. [39] determined the thermal insulation performance of nonwoven aerogel-encapsulated composites using an Alambeta tester. The aerogel composites consisted of three layers: a support layer, a base layer on the bottom, and a face layer on the surface. Aerogel granules were encapsulated in the support layer. Xiong et al. observed that the composites with aerogel-filled voids exhibited a slight decrease in the thermal conductivity (by approximately $5-9 \times 10^{-3} \mathrm{~W} / \mathrm{mK}$ ) and a small rise in the thermal resistance (by approximately $20-50 \times 10^{-3} \mathrm{Km}^{2} / \mathrm{W}$ ) [29]. Analysis indicated that nonwoven aerogel-encapsulated composites significantly enhanced the thermal insulation. The effects of aerogel on thermal insulation properties were confirmed in the presented study: the thermal conductivity of composites was higher than that of the fabric, while their thermal resistance was lower or similar, depending on the composition of coating. As can be seen, the coating of textiles could reduce the heat convection and consequently lower the thermal resistance.
In a study investigating nonwoven polyester/polyethylene fabrics treated with aerogel, Venkataraman et al. [40] found the thermal resistance to be a function of fabric thickness. They reported that the thicker samples exhibited the higher thermal resistance, while the observed lower heat losses were associated with the space insulated by the fabric (which may be attributed to aerogel particles present in the fabric). Results of the present study on composites showed that the aerogel coatings are consistent with those findings. Here, it was also observed that the higher the aerogel content, the greater the material thickness $(0 \%-0.59 \mathrm{~mm}, 7 \%-0.81 \mathrm{~mm}$, $14 \%-1.01 \mathrm{~mm}$ ) (Figure 1) and the higher the thermal resistance $\left(0 \%-14.9 \times 10^{-3} \mathrm{~W} / \mathrm{mK}, 6 \%-18.6 \times 10^{-3} \mathrm{~W} / \mathrm{mK}\right.$, $7 \%-27.7 \times 10^{-3} \mathrm{~W} / \mathrm{mK}$ ) (Figure 8). At aerogel content $(14 \%)$, no additional increment in the thermal resistance was obtained $\left(25.7 \times 10^{-3} \mathrm{~W} / \mathrm{mK}\right)$ despite a further increase in thickness. Probably, this may be due to the achievement of a certain level of aerogel filling of composite surfaces.

\section{Conclusions}

The presented findings demonstrate the considerable application potential of aerogels in materials designed for the heat protective clothing. The coating of meta-aramid fabric with dispersions containing silica aerogel particles improved its resistance to thermal radiation. The $\mathrm{RHTI}_{24}$ increased by approximately 15 and $25 \%$ for composites with coatings containing 14 and $17 \%$ of aerogel by weight, respectively. The composite with a coating containing $6 \%$ of aerogel exhibited a significant increase in the thermal conductivity $\left(47.9 \times 10^{-3} \mathrm{~W} /\right.$ $\mathrm{mK})$. The incorporation of 7 and $14 \%$ of aerogel reduced the thermal conductivity of both composites by $39.2 \times 10^{-3} \mathrm{~W} / \mathrm{mK}$. The thermal resistance of those composites was higher than those without aerogel (by $27.7 \times 10^{-3} \mathrm{~W} / \mathrm{mK}$ and $25.6 \times 10^{-3} \mathrm{~W} /$ $\mathrm{mK}$, respectively). Their initial thermal degradation temperature was similar to coatings without aerogel (approximately $360^{\circ} \mathrm{C}$ ).

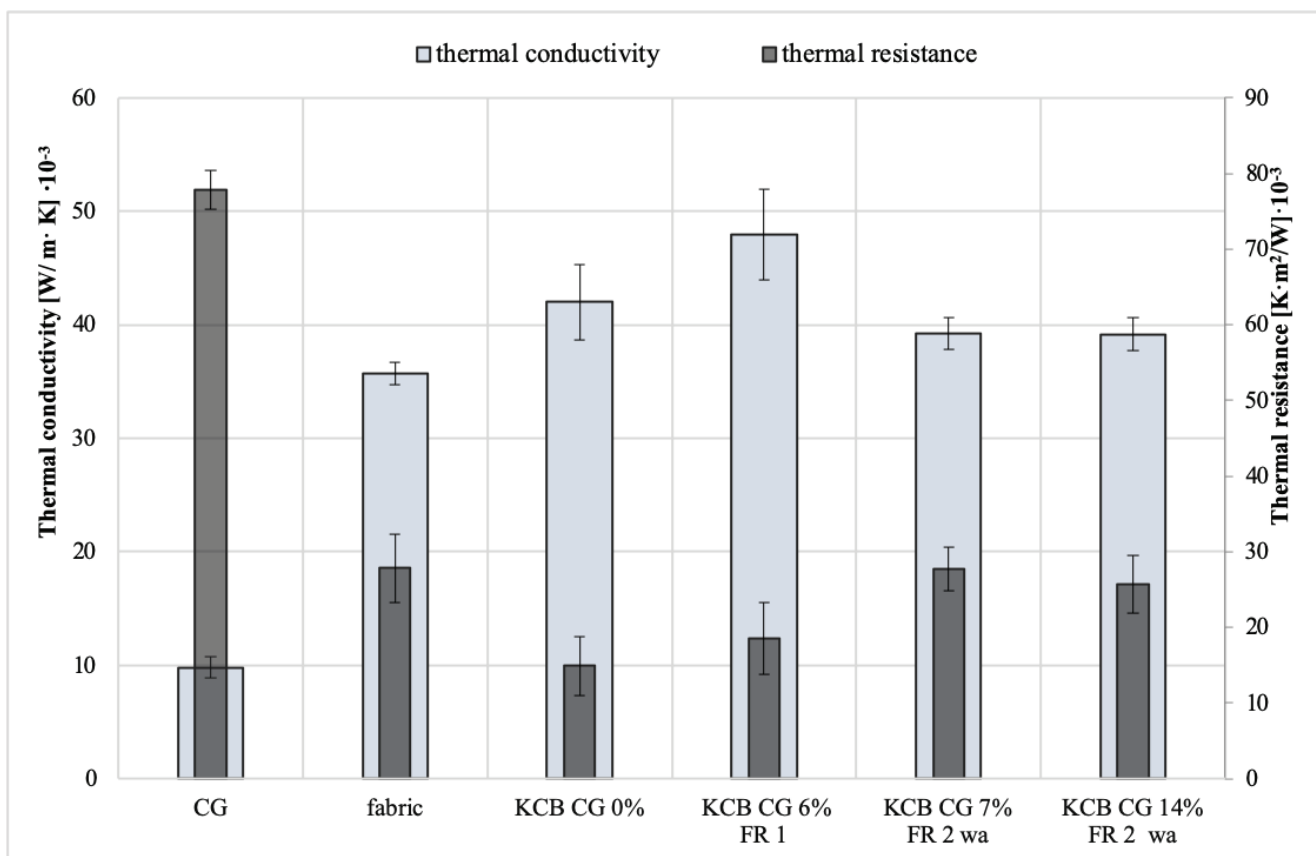

Figure 8. Thermal conductivity and thermal resistance of composites containing polymeric coatings with and without aerogel. 
The coating of fabrics with polymeric dispersions containing the aerogel entailed substantial difficulties related to the aerogel fragmentation and loss of insulation properties. The acquired SEM images demonstrated that the processes of paste preparation and fabric coating resulted in a significant decrease in aerogel particle sizes. SEM/EDS analysis revealed variation of silicon content depending on the paste composition and aerogel content in the coating. The crushing of aerosol particles is attributable to their substantial brittleness. This preliminary study showed that the fabric coating process with polymeric dispersions containing the aerogel did not lead to the improved resistance to thermal radiation. Therefore, further research should be addressed to the possibility of modifying aerogel to increase its crushing resistance.

\section{Funding}

The present publication is based on the results of Phase IV of the National Program "Safety and working conditions improvement" funded in the years 2017-2019 in the area of research and development work by the Ministry of Science and Higher Education/The National Centre for Research and Development. The Program's coordinator is the Central Institute for Labour Protection-National Research Institute.

Declaration of Conflicting Interests: No conflict of interest.

\section{Acknowledgements}

The authors thank BOCHEMIA Company, Radom, Poland for help with obtaining materials and applying aerogel mixtures to the fabric. They also thank Institute of Architecture of Textiles, Lodz University of Technology, Poland for enabling tests of thermal conductivity and resistance. The SEM/EDS analysis was done using a microscope purchased under the Project WND-RPLD.03.01.00-00-001/09 within Łukasiewicz Research Network-Textile Research Institute. TG/DTG analysis was performed using an apparatus purchased under the project POIG.01.03.01-00-004/08 Functional nano- and micromaterials-NANOMITEX within Łukasiewicz Research Network-Textile Research Institute.

\section{References}

[1] Irzmańska, E. (2016). The microclimate in protective fire fighter footwear: foot temperature and air temperature and relative humidity. Autex Research Journal, 16, 75-79.

[2] Collin, A., Marchand, A., Kadi, A., Acem, Z., Boulet, P. et al. (2015). Study on visible-IR radiative properties of personal protective clothings for firefighting. Fire Safety Journal, 71, 9-19.

[3] Gralewicz, G., Owczarek, G. (2016). Analysis of the selected optical parameters of filters protecting against hazardous infrared radiation. International Journal of Occupational Safety and Ergonomics, 22, 305-309.

[4] Peng, L., Su, B., Yu, A., Jiang, X. (2019). Review of clothing for thermal management with advanced materials. Cellulose, 26(11), 6415-6448.
[5] Iswar, S., Griffa, M., Kaufmann, R., Beltran, M., Huber, L. et al. (2019). Effect of aging on thermal conductivity of fiber-reinforced aerogel composites: an X-ray tomography study. Microporous and Mesoporous Materials, 278, 289296.

[6] Thapliyal, P. C., Singh K. (2014). Aerogels as promising thermal insulating materials: an overview. Journal of Materials, Article ID 127049, 1-10.

[7] Venkataraman, M., Mishra, R., Kotresh, T. M., Militky, J., Jamshaid H. (2016). Aerogels for thermal insulation in high-performance textiles. Textile Progress, 48, 55-118.

[8] Bhuiyan, M. R., Wang, L., Shaid, A., Jahan, I., Shanks, R. A. (2020). Silica aerogel-integrated nonwoven protective fabrics for chemical and thermal protection and thermophysiological wear comfort. Journal of Materials Science, 55, 2405-2418.

[9] Nosrati, R. H., Berardi, U. (2018). Hygrothermal characteristics of aerogel-enhanced insulating materials under different humidity and temperature. Energy and Buildings, 158, 698-711.

[10] Berardi, U., Zaidi S. M. (2019). Characterization of commercial aerogel-enhanced blankets obtained with supercritical drying and of a new ambient pressure drying blanket. Energy and Buildings, 198, 542-552.

[11] Fantucci, S., Lorenzati, A., Capozzoli, A., Perino, M. (2019). Analysis of the temperature dependence of the thermal conductivity in vacuum insulation panels. Energy and Buildings, 183, 64-74.

[12] Lorenzati, A., Fantucci, S., Capozzoli, A., Perino, M. (2015) VIPs thermal conductivity measurement: test methods, limits uncertainty. Energy Procedia, 78, 418-423.

[13] Lakatos, Á., Csarnovics, I. (2019). Influence of thermal annealing on structural properties of silica aerogel super insulation material. Journal of Thermal Analysis and Calorimetry, 1-9. https://doi.org/10.1007/s10973-01909043-5.

[14] Ślosarczyk, A. (2017). Recent advances in research on the synthetic fiber based silica aerogel nanocomposites. Nanomaterials (Basel), 7(2), 44.

[15] Greszta, A., Krzemińska, S., Okrasa, M. (2019). Influence of aging factors on the properties of aerogels with different degree of granulation. Fibres and Textiles in Eastern Europe, 4, 50-58.

[16] Höffele, S., Russell, S. J., Brook, D. B. (2005). Lightweight nonwoven thermal protection fabrics containing nanostructured materials. Nonwovens Research Academy EDANA (Geneva).

[17] Shaid, A., Furgusson, M., Wang, L. (2014). Thermophysiological comfort analysis of aerogel, nanoparticle incorporated fabric for fire fighter's protective clothing. Chemical and Materials Engineering, 2(2), 37-43.

[18] Bhuiyan, M., Wang, L., Shaid, A., Shanks, R., Ding, J. (2019). Polyurethane-aerogel incorporated coating on cotton fabric for chemical protection. Progress in Organic Coatings, 131, 100-110.

[19] Yan, J., Choi, H. Y., Hong, Y. K., Jeong, Y. G. (2018). Thermal insulation performance of cotton and pet-based hybrid fabrics impregnated with silica aerogel via a facile dip-dry process. Fibers and Polymers, 4, 854-860. 
[20] Ackerman, W. C., Field, R. J., Poetter, F. J. H., Scheidemantel, B. (2002). Heat resistant aerogel insulation composite and method for its preparation; aerogel binder composition and method for its preparation. European Patent No. 1469939A1.

[21] Cavdar, A. D., Torun, S. B., Ertas, M., Mengeloglu, F. (2018). Ammonium zeolite and ammonium phosphate applied as fire retardants for microcrystalline cellulose filled thermoplastic composites. Fire Safety Journal, 107, 202-209.

[22] Chakraborty, S., Rao, A. V., Kothari, V. K., Pisal, A. A. (2019). Radiant heat protective performance of clothing assemblies with flexible aerogel-nomex nonwoven composite as thermal insulation. Indian Journal of Fibre and Textile Research, 44, 396-403.

[23] Mandal, S., Annaheim, S., Pitts, T. M., Rossi, R. M. (2018). Studies of the thermal protective performance of fabrics under fire exposure: from small-scale to hexagon tests. Textile Research Journal, 88(20), 2339-2352.

[24] Glombikova, V., Komarkova, P. (2014). The efficiency of non-flammable functional underwear. Autex Research Journal, 14, 174-178.

[25] Cabot Data Sheet. Enova Aerogel IC 3100. Retrieved March 1, 2018. Web site: http://www.cabotcorp.com/ solutions/products-plus/aerogel.

[26] EN ISO 5084:1996. Textiles. Determination of thickness of textiles and textile products.

[27] EN 12127:1997. Textile fabrics. Determination of mass per unit area using small samples.

[28] EN ISO 6942:2002. Protective clothing. Protection against heat and fire. Method of test: evaluation of materials and material assemblies when exposed to a source of radiant heat.

[29] EN ISO 11612:2015. Protective clothing. Clothing to protect against heat and flame. Minimum performance requirements.

[30] Matusiak, M. (2006). Investigation of the thermal insulation properties of multilayer textiles. Fibres Textiles in Eastern Europe, 5(59), 98-102.
[31] Kraner, Z. P., Mekjavic, I. B., Rijavec, T. (2016). Properties of laminated silica aerogel fibrous matting composites for footwear applications. Textile Research Journal, 86, 10631073.

[32] Sarawade, P. B., Kim, J. K., Hilonga, A., Viet, Q. D., Jeon, S. J. et al. (2011). Synthesis of sodium silicate-based hydrophilic silica aerogel beads with superior properties. Effect of heat-treatment. Journal of Non-Crystalline Solids, 357, 2156-2162.

[33] Krzemińska, S., Greszta, A., Różański, A., Safandowska, M., Okrasa, M. (2019). Effects of heat exposure on the properties and structure of aerogels for protective clothing applications. Microporous and Mesoporous Materials, 285, 43-55.

[34] Williams, M. K., Smith, T. M., Roberson, L. B., Yang, F., Nelson, G. L. (2010). Flame retardant effects of aerogel and nanosilica on engineered polymers. In: ICCE-18 International Community of Composite Engineering, Anchorage, United States, Paper no. 20110002953.

[35] Li, Z., Cheng, X., Shi, L., He, S., Gong, L. et al. (2016). Flammability and oxidation kinetics of hydrophobic silica aerogels. Journal of Hazard Materials, 320, 350-358.

[36] Song, H., Yang, H., Chen, X. (2017). Facile synthesis of highly porous silica aerogel granules and its burning behavior under radiation. Journal of Sol-Gel Science and Technology, 82, 407-416.

[37] Oh, K. S., Lee, J. K., Bae, D. S., Son, J. H. (2018). Method for manufacturing low-dust high-insulation aerogel blanket. European Patent No. 3281928 A1.

[38] Shang, L., Lyu, Y., Han, W. (2019). Microstructure and thermal insulation property of silica composite aerogel. Materials, 12, 1-11.

[39] Xiong, X., Yang, T., Mishra, R., Kanai, H., Militky, J. (2017). Thermal and compression characteristics of aerogelencapsulated textiles. Journal of Industrial Textiles, 47, 1998-2013.

[40] Venkataraman, M., Mishra, R., Militky, J. (2017). Comparative analysis of high performance thermal insulation materials. Journal of Textile Engineering and Fashion Technology, 2(3), 401-409. 